\title{
Nasopharyngeal pH and gastroesophageal reflux in children with chronic respiratory disease
}

\author{
José Cesar da Fonseca Junqueira, 1 Francisco José Penna²
}

\begin{abstract}
Objectives: The aim of this case-control study was to evaluate the nasopharyngeal $\mathrm{pH}(\mathrm{NasopH})$ in children with normal or abnormal pH-metry in two groups of patients: 1) children presenting gastroenterological symptoms; and 2) children with chronic respiratory symptoms.
\end{abstract}

Methods: From February 2004 to January 2005, all consecutive patients referred for 24-hour pH-metry and in whom gastroesophageal reflux disease was suspected were enrolled in a prospective study. They were assigned to four groups: gastroenterological symptoms with normal (A) or abnormal (B) pH-metries (GG), and chronic respiratory symptoms with normal (C) or abnormal (D) pH-metries (RG). NasopH was measured for 5 minutes, before the 24-hour test was performed.

Results: Thirty-eight pH-metry tests were included (20 in the RG and 18 in the GG). Abnormal pH-metry results were observed in 11 patients in the GG and in 12 in the RG. NasopH means were 6.3273 and 5.6917, respectively $(\mathrm{p}<0.0001)$. Average nasopharyngeal $\mathrm{pH}$ was 5.6917 among the $12 \mathrm{RG}$ patients with abnormal $\mathrm{pH}$-metry results and 6.5000 among the remaining eight patients with normal test results $(p=0.0006)$. Analysis of the RG with a receiver operating characteristic (ROC) curve showed pH of 5.8 as cutoff point (sensitivity of $91.7 \%$ and specificity of $87.5 \%$ ). The area below the ROC curve was 0.870 .

Conclusions: Nasopharyngeal pH is significantly lower among patients in the RG presenting abnormal pH-metry results. A 5.8 NasopH has good sensitivity and specificity and can be used as a screening test in patients with chronic respiratory diseases to select those for whom conventional 24-hour pH-metry is indicated.

J Pediatr (Rio J). 2007;83(3):225-232: Gastroesophageal reflux/complications/diagnosis, child, evaluation studies, nasopharynx, esophageal pH monitoring.

\section{Introduction}

Gastroesophageal reflux disease (GERD) is a frequent problem in the pediatric population. ${ }^{1}$ Gastroesophageal reflux (GER) has been suggested as one of the triggers of asthmatic processes. Its prevalence among patients with asthma seems to be variable, with values ranging from 25 to
$75 \%,{ }^{2,3}$ and is subject to controversy. Euler et al. in 1979 detected GER in $63 \%$ out of a group of 30 children aging 1 to 18 months and presenting recurrent chronic pulmonary disease. ${ }^{4}$ Khoshoo et al. ${ }^{5}$ observed a reduction of at least $50 \%$ in the volume of asthma medication needed by patients who had been using proton pump inhibitors during 1 year.

1. Doutor. Professor adjunto, Universidade Federal do Rio de Janeiro (UFRJ), Rio de Janeiro, RJ, Brasil. Serviço de Gastroenterologia Pediátrica, Instituto de Puericultura e Pediatria Martagão Gesteira, Rio de Janeiro, RJ, Brasil.

2. Doutor, Universidade Federal de São Paulo (UNIFESP), São Paulo, SP, Brasil. Professor titular, Universidade Federal de Minas Gerais (UFMG), Belo Horizonte, MG, Brasil.

The present paper includes some data from the author's doctoral thesis defended at UFMG, Belo Horizonte, MG, Brazil. The data in this study were collected from Hospital Universitário Gaffrée e Guinle (HUGG), Universidade Federal do Estado do Rio de Janeiro (UNIRIO), Rio de Janeiro, RJ, Brazil. The study was approved by the Department of General Medicine, School of Medicine and Surgery, and by the Ethics Research Committees, HUGG and UFMG, Brazil.

Manuscript received Jul 17 2006, accepted for publication Feb 282007.

Suggested citation: Junqueira JC, Penna FJ. Nasopharyngeal pH and gastroesophageal reflux in children with chronic respiratory disease. J Pediatr (Rio J). 2007;83(3):225-232.

doi 10.2223/JPED.1634 
Holinger \& Sanders reported, in 72 children studied presenting chronic cough for over 1 month and normal thorax radiography, a GER prevalence of $15 \% .^{6}$ GER seems to contribute to chronic sinus disease in children ${ }^{7}$ and may manifest itself as an extra-esophageal manifestation, such as nasopharyngitis, leading to ear disease. ${ }^{8}$ More studies are necessary to clarify the role of reflux in diseases affecting the respiratory tract.

Contencin et al. reported, in 1989, nasopharyngeal pH variation in patients presenting GER and rhinopharyngitis. In 1991, Contencin \& Narcy ${ }^{8}$ stated that "The role of gastroesophageal reflux has been demonstrated in some cases of bronchitis and laryngitis especially in children. In adults, GER-related laryngitis has also been mentioned." The investigation of nasopharyngeal $\mathrm{pH}$ in 31 children, 13 of whom presenting gastroesophageal reflux, rhinitis and rhinopharyngitis and 18 control patients with or without reflux, showed that the $\mathrm{pH}$ drops were more important in most of the GER/rhinitis cases than in controls (with cutoff point of $\mathrm{pH} 6$ ). From these results, the authors proposed that $\mathrm{pH}$ lowering was directly related to episodes of acid reflux, which affect the upper respiratory tract, being responsible for the origin and maintenance of inflammation in the respiratory tract mucosa. Further studies were suggested to confirm the hypothesis.

Since these studies were published, little attention has been given to the relationship between nasopharyngeal $\mathrm{pH}$ and gastroesophageal reflux. A systematic review of the PubMed database, with the keywords gastroesophageal reflux and nasopharyngeal $\mathrm{pH}$, resulted in only a few reports relating nasopharyngeal $\mathrm{pH}$ and rhinopharyngitis or other respiratory conditions. ${ }^{7,9}$ James \& Ewer describe a relationship between acid oropharyngeal $\mathrm{pH}$ and the presence or absence of gastroesophageal reflux. This study involving preterm infants, with primary symptoms of rumination and xanthine-resistant apnea, but without infections, showed $89 \%$ sensitivity, $80 \%$ specificity, a positive predictive value of $94 \%$ and negative predictive value of $67 \%$ for an association between acid oropharyngeal $\mathrm{pH}$ and gastroesophageal reflux. ${ }^{10}$

Although pH-metry is not a highly invasive method, it is not possible to be performed in all patients with chronic respiratory manifestations. The question then is how to select those in whom 24-hour pH monitoring should be performed.

The objective of the present observational case-control study $^{11}$ was to determine the relationship between nasopharyngeal $\mathrm{pH}$ and conventional 24-hour $\mathrm{pH}$ monitoring in patients with gastroenterological and chronic respiratory symptoms and to evaluate if the nasopharyngeal $\mathrm{pH}$ could be used as a screening test of GER in children with respiratory symptoms.

\section{Methods}

\section{Patients}

All consecutive patients, aged between 6 months and 12 years, referred for esophageal 24-hour $\mathrm{pH}$ monitoring during the period from February 2004 to January 2005, were enrolled in the study. They were assigned to four groups: A) gastroenterological group with abnormal $\mathrm{pH}$-metry; B) gastroenterological group with normal pH-metry; C) respiratory group with abnormal $\mathrm{pH}$-metry; and $\mathrm{D}$ ) respiratory group with normal $\mathrm{pH}$-metry. Patients presenting both respiratory and gastroenterological symptoms were included in the respiratory group. Groups A, B and D were used as controls for group $\mathrm{C}$.

\section{Inclusion criteria}

\section{Gastroenterological group (GG)}

Patients presenting vomits, dyspepsia, upper gastrintestinal bleeding, chronic abdominal pain, dysphagia, or any other gastroenterological symptoms requiring diagnosis through 24-hour monitoring of esophageal $\mathrm{pH}$.

\section{Respiratory group ( $R G)$}

Otitis, sinusitis, laryngitis, epiglottitis and recurrent stridor: Three or more episodes in the last 6 months and vocal cord disorders; referred by a specialized physician (otolaryngologist). ${ }^{12}$

Mild or severe persistent asthma and recurrent pneumonias: three or more episodes in the last 6 months; radiologically diagnosed pneumonias; referred by a specialized physician (pediatric pulmonologist).

\section{Exclusion criteria}

Patients using any oral or inhaled bronchodilator therapy, oral, nasal or inhaled corticosteroids or antibiotics at the time of esophageal $\mathrm{pH}$ monitoring were excluded. Patients using any of these drugs interrupted treatment 1 week before testing. Other exclusion criteria were neurological impairment of any etiology; any congenital esophageal, gastric or intestinal pathology; esophagus or stomach surgery; or conditions in which, for any reason, esophageal $\mathrm{pH}$ monitoring could not be conducted for at least 18 hours.

\section{pH monitoring}

$\mathrm{H} 2$ blockers/proton pump inhibitors, prokinetic and antacid treatments were discontinued 8 days before the 24-hour monitoring. A 6-hour fasting period was required prior to the test. Intraesophageal 24-hour pH monitoring was performed using an antimony electrode. This electrode was linked to a digital data logger (SMP2128, Sigma Instruments ${ }^{\circledR}$, Belo Horizonte, Brazil). The probe was calibrated at $\mathrm{pH} 7.0$ and $\mathrm{pH} 1.0$, before the procedure, using appropriate buffer solutions. Upon completion of the study, 
the $\mathrm{pH}$-monitoring tracings were analyzed by EsograpH 3.0 software (Sigma Instruments ${ }^{\circledR}$, Belo Horizonte, Brazil). The probe was inserted through the right nostril and the position was assessed using Strobel's formula. ${ }^{13}$ When misplaced, the probe was repositioned and the position was confirmed by fluoroscopy. During the 24-hour study period, patients' parents were asked to keep a detailed diary of activities, food intake, symptoms, wake and sleep periods and posture. The esophageal $\mathrm{pH}$ monitoring test was considered to be abnormal when time of $\mathrm{pH} \leq 4.0$ was greater than $5 \%$ of the duration of the $\mathrm{pH}$ monitoring study, for children over 1 year old, ${ }^{14}$ and greater than $10 \%$ for children younger than 1 year. ${ }^{15}$ Before recording the data, nasopharyngeal $\mathrm{pH}$ was measured every minute for 5 minutes. The position of the electrode, placed in the nasopharynx, was determined as the distance between the right nostril and one fourth of the length of the probe, according to Strobel's formula. ${ }^{13}$ Nasopharyngeal $\mathrm{pH}$ was considered as the mean of the five measurements.

\section{Statistical analysis}

Data are presented using descriptive statistics. Statistical calculations were performed with the MedCalc ${ }^{\circledR}$ software, version 9.1.01 (MedCalc Software, Mariakerke, Belgium). Results were considered significant if $p<0.05$ by unpaired two-tailed Student's $t$ test for comparison between groups. The sample size was calculated retrospectively taking into account the required significance level and power of the test (nasopharyngeal pH), using Type I error - alpha of 0.05 and Type II error - beta of 0.2 and the difference between nasopharyngeal $\mathrm{pH}$ values and standard deviations found when the different groups studied were compared. ${ }^{16}$ Receiver operating characteristic (ROC) analyses were carried out. The model plots sensitivity vs. 1-specificity for each possible value of a test. The area under the curve (AUC) shows the ability of a test to discriminate between disease and nondisease, with increasing discriminatory ability with an increasing area. ${ }^{17}$

\section{Ethical considerations}

The study was approved by the ethical committees of the institutions involved in the project (Universidade Federal do Estado do Rio de Janeiro and Universidade Federal de Minas Gerais). An informed consent was obtained from the parents/legal guardians of all participating children, and assent was obtained before the performance of $\mathrm{pH}$ nasopharyngeal measurement and the 24-hour esophageal monitoring.

\section{Results}

Thirty-eight out of $54 \mathrm{pH}$-metry tests performed were included in the study. Twenty in the RG and 18 in the GG. Mean age was 59.05 months, (age range, 14 to 116 months).
Twenty girls and 18 boys. Sixteen patients were excluded: three were neurologically impaired, two had undergone previous esophagus surgery, in five esophageal $\mathrm{pH}$ monitoring lasted less than 18 hours, one used nasal corticosteroids on the day of $\mathrm{pH}$ monitoring, two were older than 12 years and three were less than 6 months old.

The most prevalent symptoms in the studied group were vomiting, asthma and abdominal pain. Abdominal pain, alone or associated with vomiting, was the most frequently reported symptom in patients in the gastroenterological group, whereas in the respiratory group asthma, alone or associated with chronic sinusitis and/or vomiting and abdominal pain, was the most frequently reported symptom.

Considering all subjects ( $G G+R G$ ), nasopharyngeal $p H$ had a normal distribution with a mean of 6.2211 (95\% CI 6.0453-6.3968) and a median of 6.2000 (95\%CI 5.8000-6.5000) with a variance of 0.2860 and standard deviation of 0.5348 (Figure 1). In the RG, the mean nasopharyngeal $\mathrm{pH}(6.0150)$ was significantly lower ( $p=0.00103)$ than the GG (6.4500). Abnormal pH-metry results were observed in 11 patients from the GG and in 12 of the RG, with a mean nasopharyngeal $\mathrm{pH}$ of 6.3273 and 5.6917, respectively ( $p<0.0001)$. When compared, nasopharyngeal pH (GG $=6.6429$ vs. $\mathrm{RG}=6.5000$, $p=0.5826)$, no statistically significant differences were observed. Within the respiratory group, the mean nasopharyngeal $\mathrm{pH}$ was very different when considering patients with normal or abnormal $\mathrm{pH}$-metry results, with mean $\mathrm{pH}$ values of 5.6917 and 6.5000 , respectively $(p=0.0006)$. Finally, in the gastroenterological group, the mean nasopharyngeal $\mathrm{pH}$ was 6.3273 for the 11 patients with abnormal pH-metry results and 6.6429 for the seven ones with normal $\mathrm{pH}$-metry results with no statistically significant differences $(p=0.0764)$. In the absence of literature data when this study was started, no sample size was estimated. A retrospective calculation of sample size comparing nasopharyngeal $\mathrm{pH}$ means ( $80 \%$ power with type II error of $20 \%$ and type I error of $5 \%$ ) confirmed that our sample size was adequate to compare GG and RG with abnormal $\mathrm{pH}$-metries and nasopharyngeal values found in RG with abnormal and normal pH-metries. (Table 1 and Figure 2).

ROC analyses were carried out with the results of the 20 patients of the RG and showed the pH of 5.8 as the best cutoff point, with a sensitivity of 92.7 and specificity of 87.5 . The $95 \%$ confidence intervals for nasopharyngeal $\mathrm{pH}$ of 5.8 were 61.5-98.6 for sensitivity and 47.4-97.9 for specificity. The AUC corresponded to 0.848 . The positive (+LR) and negative (-LR) likelihood ratios were 7.33 and 0.10 , respectively (Table 2). 


\section{Discussion}

Patients with respiratory symptoms and abnormal $\mathrm{pH}$-metries have a more "acid nasopharynx" than patients in the control groups.

Asthma, as many other atopic diseases, is complex and multifactorial. And so is GERD. GER and environmental allergies are prevalent among asthmatic patients, and can often induce each other. ${ }^{18}$ There seems to exist a relationship between GER and chronic respiratory disease. In this study, $16 \mathrm{pH}$-metry tests were performed in patients with persistent mild or severe asthma, isolated or associated with other respiratory symptoms. Ten of them showed abnormal $\mathrm{pH}$-metry results, with a prevalence of $62.5 \%$. Despite some controversial reports, literature data support this association. ${ }^{19-22}$ The association between GERD and asthma seems to involve a neurological component, cytokines, inflammatory cells and, in some patients, aspiration of the refluxed stomach contents. Children with GERD and lung disease may show evidence of lung obstruction, hypoventilation and increased respiratory reactivity, but no

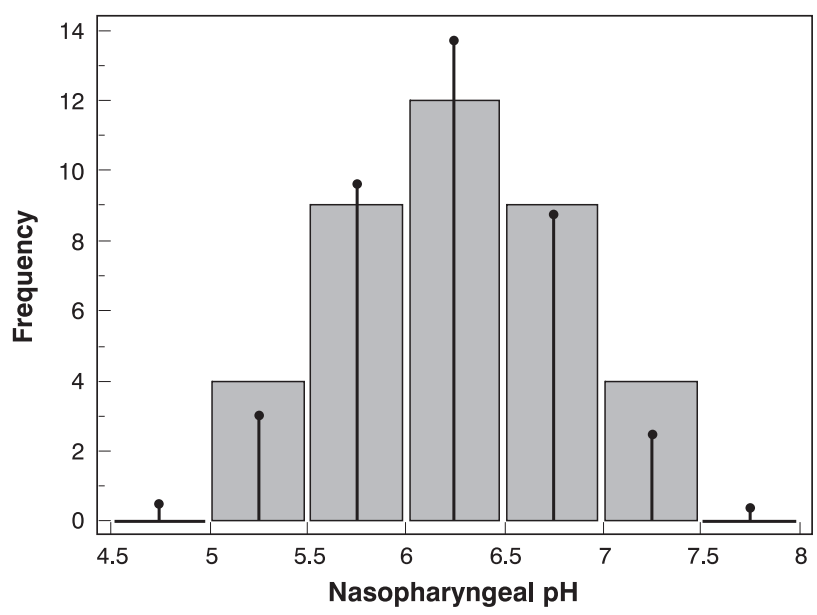

Percentiles: $2.5=5.29 ; 10=5.43 ; 25=5.80 ; 75=6.50 ; 90=7.01$; $97.5=7.10$.

Figure 1 - Nasopharyngeal pH distribution and percentiles in all subjects studied. Nasopharyngeal $\mathrm{pH}$ mean of 6.2211 (95\%CI 6.0453-6.3968) and median of 6.2000 (95\% CI 5.8000-6.5000) with a variance of 0.2860 and standard deviation of 0.5348

Table 1 - Summary of the results: mean nasopharyngeal $\mathrm{pH}$ in each group with standard deviation and Student's $t$ test (statistically, nasopharyngeal $\mathrm{pH}$ in children with respiratory symptoms can distinguish normal from abnormal 24-hour intraesophageal $\mathrm{pH}$ monitoring)

\begin{tabular}{|c|c|c|c|c|}
\hline & $\begin{array}{l}\text { Gastrointestinal } \\
\text { group }\end{array}$ & $\begin{array}{l}\text { Respiratory } \\
\text { group }\end{array}$ & $\begin{array}{c}\text { Difference/Student's } \\
t \text { test }(p)\end{array}$ & $\begin{array}{c}\text { Sample size ( } \alpha \text { and } \beta \text { error) } \\
\alpha=0.05, \beta=0.2\end{array}$ \\
\hline All patients, $n$ & 18 & 20 & & 28 \\
\hline Mean nasopharyngeal pH & $6.4500 \rightarrow$ & 6.0150 & $\rightarrow 0.4350$ & \\
\hline Standard deviation & \pm 0.3698 & \pm 0.5833 & $p=0.0103$ & \\
\hline Abnormal pH-metry, n & 11 & 12 & & 4 \\
\hline Mean nasopharyngeal pH & $6.3273 \rightarrow$ & 5.6917 & $\rightarrow 0.6356$ & \\
\hline \multirow[t]{2}{*}{ Standard deviation } & \pm 0.3849 & \pm 0.2392 & $p=0.0001$ & \\
\hline & $\downarrow$ & $\downarrow$ & & \\
\hline Normal pH-metry, n & 7 & 8 & & 175 \\
\hline Mean nasopharyngeal pH & $6.6429 \rightarrow$ & 6.5000 & $\rightarrow 0.1429$ & \\
\hline \multirow[t]{2}{*}{ Standard deviation } & \pm 0.2637 & \pm 0.6211 & $p=0.5826$ & \\
\hline & $\downarrow$ & $\downarrow$ & & \\
\hline Difference & 0.3156 & 0.8083 & & \\
\hline Student's $t$ test $(p)$ & $p=0.0764$ & $p=0.0006$ & & \\
\hline $\begin{array}{l}\text { Sample size ( } \alpha \text { and } \beta \text { error), } \\
\alpha=0.5, \beta=0.2\end{array}$ & 13 & 5 & & \\
\hline
\end{tabular}




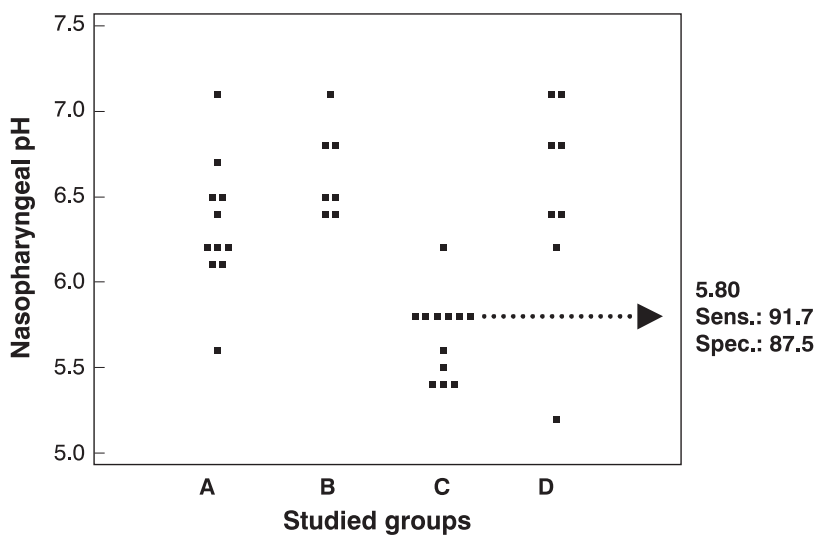

Figure 2 - Nasopharyngeal pH results: A) gastroenterological group with abnormal pH-metry; B) gastroenterological group with normal $\mathrm{pH}$-metry; $\mathrm{C}$ ) respiratory group with abnormal $\mathrm{pH}$-metry; and $\mathrm{D}$ ) respiratory group with normal pH-metry. The horizontal line is the best cutoff value of nasopharyngeal $\mathrm{pH}$ (5.8), which distinguishes normal from abnormal $\mathrm{pH}$-metry in the Respiratory group

restriction of lung volume is observed. ${ }^{23}$ It is not clear whether the acid $\mathrm{pH}$ is due to the reflux of stomach contents into the nasopharynx, or whether the reflux itself stimulates an inflammatory reaction of the mucosal system through esophageal receptors. This question deserves further investigation, with continuous and simultaneous $\mathrm{pH}$ analysis of the nasopharynx and proximal and distal esophagus, followed by biopsies of the esophagus and upper respiratory tract. GERD treatment in asthmatic patients improves asthma symptoms, but has little effect on pulmonary function. ${ }^{24}$ The understanding of the relationship between these two conditions may have important consequences in establishing an adequate treatment for these patients.

When otolaryngological diseases are considered, different studies have shown associations between GERD and hoarseness, laryngitis, chronic rhinitis, sinusitis, globus sensation, laryngomalacia, stridor, subglottic stenosis, otalgia, vocal cord granulomas and oropharyngeal dysphagia. The mechanisms responsible for these relationships, however, are not well known. ${ }^{7,25}$ In the present study, two children presented vocal cord granulomas. In one case the granuloma disappeared, whereas in the other one it was still present after 12 weeks of treatment with proton pump inhibitors (PPI).

Recent literature reports hypothesize answers to these questions. In a recent study in which the $\mathrm{pH}$ of the respiratory condensate was evaluated in children, lower values were observed in patients with respiratory diseases (cystic fibrosis and asthma) than in healthy controls. ${ }^{26}$ Another study reported that $\mathrm{pH}$ and chloride levels in the exhaled air were lower in patients with respiratory symptoms and chronic cough of different etiologies, with or without reflux, than in healthy control individuals, ${ }^{27}$ suggesting that acid $\mathrm{pH}$ is a consequence of inflammatory processes affecting the respiratory tract. The existence of proton pump activity with a functional role in normal and/or pathological laryngeal tissue has been recently suggested. ${ }^{28}$ More research is still needed for a conclusion about these processes. Is it possible that some patients with respiratory symptoms produce "acids" in the larynx, when adequately stimulated, resulting in reflux? Andréa and Tasker, in 2002, showed the presence and activity of pepsin/pepsinogen in ear secretion from patients with otitis media with effusion. ${ }^{29}$ Nevertheless, the relationship between otitis and GERD is still very controversial. ${ }^{30}$ It is also evident that acidification of the terminal esophagus should induce the production of some type of mediator able to affect more distant tissues. This can be observed, for instance, in Herbst Triad, whose symptoms include finger clubbing. When esophagitis is treated with acid secretion inhibitors, both symptoms are resolved. ${ }^{31-33}$ Other joint disorders associated with GER have been reported, showing remission after acid suppression. ${ }^{34}$

The results of this study, with sensitivity of $91.7 \%$ and specificity of $87.5 \%$, are similar to those reported by James and Ewer ( $89 \%$ sensitivity and $80 \%$ specificity). ${ }^{10}$ The ROC curve analysis showed that the best cutoff point for nasopharyngeal $\mathrm{pH}$ was 5.8. Nasopharyngeal $\mathrm{pH}$ of 6.2 had a sensitivity of $100 \%$, but a lower specificity (75\%) and a very low + LR and -LR. The AUC of 0.870 means that in $87 \%$ of the cases an individual randomly chosen from the positive group has a nasopharyngeal $\mathrm{pH}$ value lower than that presented by an individual from the negative group, also randomly selected. If nasopharyngeal $\mathrm{pH}$ results were not capable of distinguishing between abnormal and normal pH-metry, the AUC would tend toward 0.5 , corresponding to the diagonal line observed in the ROC curve. Nasopharyngeal pH can thus be considered a good test to indicate the presence of abnormal $\mathrm{pH}$-metry in patients with chronic respiratory diseases, since the area under the ROC curve is within the 0.80 to 0.90 interval. The oscillation of the $95 \% \mathrm{CI}$ between 0.645 and 0.974 means that the test (nasopharyngeal $\mathrm{pH}$ ) is capable of discriminating between the two groups (abnormal and normal $\mathrm{pH}$-metry results) as value 0.5 is not included in the results. The positive and negative likelihood ratios (+LR and $-L R$ ) of 7.33 and 0.10 , respectively, were observed in the present study at a cutoff of 5.8, showing a moderate probability that a nasopharyngeal $\mathrm{pH}$ of 5.8 is to be expected in a patient presenting abnormal 24-hour $\mathrm{pH}$-metry results, when compared to the probability that the same values will be found in a patient with normal $\mathrm{pH}$-metry results.

Despite the fact that in this study, patients had different respiratory complaints (asthma, rhinitis, otitis and 
laryngitis), it confirms the two studies by Contencin et al. In the first one, published in 1989, a control group of children without rhinopharyngitis and GER presented a more stable nasopharynx $\mathrm{pH}$ (6.7 to 7.4) while the group with GER and mucosal obstruction of the nose and pharynx had a rhinopharyngeal $\mathrm{pH}$ larger variation. In the other study, published in $1991,{ }^{8}$ the $\mathrm{pH}$ drops were more important in most of the GER/rhinitis where falls in rhinopharyngeal $\mathrm{pH}$ were found to be more frequent and to last longer in children presenting chronic rhinopharyngitis and gastroesophageal reflux than in two control groups without rhinopharyngitis and with or without GER. However, the technique used does not allow us, as with Contencin, to assess the true origin of these $\mathrm{pH}$ values. ${ }^{8}$

The study suggests that patients with abnormal results in esophageal $\mathrm{pH}$ studies have a more acidic environment in their upper respiratory tract, which could be explained by two different mechanisms: the gastric content reaches the nasopharynx or there is a more acidic environment per se resulting in interference with esophageal motility with reflux. It is probable that new technologies will be necessary to answer these questions.
Finally, some points about the methodology used in this study must be considered. The number of patients that can be studied in case-control studies is often limited by the rarity of the condition or the intervention under investigation. Under this circumstance, statistical confidence can be increased by taking more than one control per case. In this study, cases and controls came from the same population at risk for GER, but it was not possible to achieve an adequate number for the control group in order to add more credibility to the results. In spite of the size of the control group and possible bias because of the selection of cases and controls (wide age range, different feeding times and starting point for data collection), the analyses based on a single 5-minute measurement of nasopharyngeal $\mathrm{pH}$ lay the groundwork for further research on this subject. Larger and in-depth studies may be required to provide adequate statistical power to these questions and confirm these results. Maybe an interesting study design could use special probes with multiple sensors with continuous and simultaneous 24-hour monitoring of nasopharyngeal $\mathrm{pH}$ and of the $\mathrm{pH}$ of the lower and upper esophagus. In conclusion, nasopharyngeal $\mathrm{pH}$ evaluation may be capable of distinguishing between patients with GER

Table 2 - Sensitivity, specificity and positive (+LR) and negative (-LR) likelihood ratios of several nasopharyngeal pH values

\begin{tabular}{|c|c|c|c|c|}
\hline Nasopharyngeal pH & $\begin{array}{c}\text { Sensitivity } \\
(95 \% \mathrm{CI})\end{array}$ & $\begin{array}{c}\text { Specificity } \\
(95 \% \mathrm{CI})\end{array}$ & +LR & -LR \\
\hline$<5.2$ & $(0.0-26.6)$ & $100.0(62.9-100.0)$ & & 1.00 \\
\hline$\leq 5.2$ & $(0.0-26.6)$ & $87.5(47.4-97.9)$ & 0.00 & 1.14 \\
\hline$\leq 5.4$ & $25.0(5.8-57.2)$ & $87.5(47.4-97.9)$ & 2.00 & 0.86 \\
\hline$\leq 5.5$ & $33.3(10.1-65.1)$ & $87.5(47.4-97.9)$ & 2.67 & 0.76 \\
\hline$\leq 5.6$ & $41.7(15.3-72.2)$ & $87.5(47.4-97.9)$ & 3.33 & 0.67 \\
\hline$\leq 5.8^{*}$ & $91.7(61.5-98.6)$ & 87.5 (47.4-97.9) & 7.33 & 0.10 \\
\hline$\leq 6.2$ & $100.0(73.4-100.0)$ & $75.0(35.0-96.1)$ & 4.00 & 0.00 \\
\hline$\leq 6.4$ & $100.0(73.4-100.0)$ & $50.0(16.0-84.0)$ & 2.00 & 0.00 \\
\hline$\leq 6.8$ & $100.0(73.4-100.0)$ & $25.0(3.9-65.0)$ & 1.33 & 0.00 \\
\hline$\leq 7.1$ & $100.0(73.4-100.0)$ & $0.0(0.0-37.1)$ & 1.00 & \\
\hline
\end{tabular}

$95 \% \mathrm{CI}=95 \%$ confidence interval $;+\mathrm{LR}=$ positive likelihood ratio; $-\mathrm{LR}=$ negative likelihood ratio.

* Best cutoff point for nasopharyngeal $\mathrm{pH}$. 
plus recurrent respiratory disease from patients with recurrent respiratory disease without GER.

\section{References}

1. Costa AJ, Silva GA, Gouveia PA, Pereira Filho EM. Prevalencia de refluxo gastroesofagico patologico em lactentes regurgitadores. J Pediatr (Rio J). 2004;80:291-5.

2. Mogica Martinez MD, Paredes Cruz E, Tenorio Pastrana MA, Rodriguez Castellon J, Molina Ortiz C, del Rosario Canseco Raymundo $\mathrm{M}$, et al. [Prevalence of hiatal hernia and chronic esophagitis in adult asthmatic patients]. Rev Alerg Mex. 2001;48:145-50.

3. Rudolph CD, Mazur LJ, Liptak GS, Baker RD, Boyle JT, Colletti RB, et al. Guidelines for evaluation and treatment of gastroesophageal reflux in infants and children: recommendations of the North American Society for Pediatric Gastroenterology and Nutrition. J Pediatr Gastroenterol Nutr. 2001;32 Suppl 2:S1-31.

4. Euler AR, Byrne WJ, Ament ME, Fonkalsrud EW, Strobel CT, Siegel SC, et al. Recurrent pulmonary disease in children: a complication of gastroesophageal reflux. Pediatrics. 1979;63:47-51.

5. Khoshoo V, Le T, Haydel RM Jr., Landry L, Nelson C. Role of gastroesophageal reflux in older children with persistent asthma. Chest. 2003;123:1008-13.

6. Holinger LD, Sanders AD. Chronic cough in infants and children: an update. Laryngoscope. 1991;101(6 Pt 1):596-605.

7. Phipps CD, Wood WE, Gibson WS, Cochran WJ. Gastroesophageal reflux contributing to chronic sinus disease in children: a prospective analysis. Arch Otolaryngol Head Neck Surg. 2000;126:831-6.

8. Contencin P, Viala P, Mashako L, Lachiver X, Maherzi A, Francois $\mathrm{M}$, et al. Measurement of $\mathrm{pH}$ of the rhinopharynx in children with gastroesophageal reflux. Presse Med. 1989;18:13-6.

9. Conley SF, Werlin SL, Beste DJ. Proximal pH-metry for diagnosis of upper airway complications of gastroesophageal reflux. J Otolaryngol. 1995;24:295-8.

10. James ME, Ewer AK. Acid oro-pharyngeal secretions can predict gastro-oesophageal reflux in preterm infants. Eur J Pediatr. 1999;158:371-4.

11. Walliser H, Christoph B, Preisler B, Uschmann K, Rose W. [Comparative studies on premedication and general anesthesia for endoscopies of the upper airways]. Z Erkr Atmungsorgane. 1986; 166:148-58.

12. Issing WJ, Gross M, Tauber S. [Manifestations of gastroesophageal reflux in the otorhinolaryngology tract]. Laryngorhinootologie. 2001;80:464-9.

13. Strobel CT, Byrne WJ, Ament ME, Euler AR. Correlation of esophageal lengths in children with height: application to the Tuttle test without prior esophageal manometry. J Pediatr. 1979;94:81-4.
14. Carroccio A, Cavataio F, Acierno E, Montalto G, Lorello D, Tumminello $\mathrm{M}$, et al. Use of 24-hour oesophageal $\mathrm{pH}$-metry for the detection of gastro-oesophageal reflux in infants: what is the ideal score and the optimal threshold? A receiver-operatingcharacteristic analysis. Ital J Gastroenterol Hepatol. 1997;29:297-302.

15. Bagucka B, Badriul H, Vandemaele K, Troch E, Vandenplas $Y$. Normal ranges of continuous $\mathrm{pH}$ monitoring in the proximal esophagus. J Pediatr Gastroenterol Nutr. 2000;31:244-7.

16. Pathak DS, Meinhold JM, Fisher DJ. Research design: sampling techniques. Am J Hosp Pharm. 1980;37:998-1005.

17. Reiser B. Measuring the effectiveness of diagnostic markers in the presence of measurement error through the use of ROC curves. Stat Med. 2000;19:2115-29.

18. McDowell KM. Pathophysiology of asthma. Respir Care Clin N Am. 2000;6:15-26.

19. Jain A, Patwari AK, Bajaj P, Kashyap R, Anand VK. Association of gastroesophageal reflux disease in young children with persistent respiratory symptoms. J Trop Pediatr. 2002; 48:39-42.

20. Harding SM. Gastroesophageal reflux: a potential asthma trigger. Immunol Allergy Clin North Am. 2005;25:131-48.

21. Everett CF, Kastelik JA, Mulrennan SA, Morice AH. Predictors of therapy resistant asthma. Thorax. 2004;59:270-1; author reply 270-1.

22. Duffey P. Atypical manifestations of gastrooesophageal reflux. J R Soc Med. 2004;97:99.

23. Allen JL, Wohl ME. Pulmonary function in older children and young adults with gastroesophageal reflux. Clin Pediatr (Phila). 1986;25:541-6.

24. Pascale JA, Mims LC, Greenberg MG, Alexander JB. Gastric response in low birth weight infants fed various formulas. Biol Neonate. 1978;34:150-4.

25. Orenstein SR. An overview of reflux-associated disorders in infants: apnea, laryngospasm, and aspiration. Am J Med. 2001;111 Suppl 8A:60S-3S.

26. Carpagnano GE, Barnes PJ, Francis J, Wilson N, Bush A, Kharitonov SA. Breath condensate $\mathrm{pH}$ in children with cystic fibrosis and asthma: a new noninvasive marker of airway inflammation? Chest. 2004;125:2005-10.

27. Niimi A, Nguyen LT, Usmani O, Mann B, Chung KF. Reduced pH and chloride levels in exhaled breath condensate of patients with chronic cough. Thorax. 2004;59:608-12.

28. van den Abbeele T, Couloigner V, Faure C, Narcy P. The role of 24 $\mathrm{h} \mathrm{pH}$-recording in pediatric otolaryngologic gastro-esophageal reflux disease. Int J Pediatr Otorhinolaryngol. 2003;67 Suppl 1:S95-100.

29. Tasker A, Dettmar PW, Panetti M, Koufman JA, P Birchal J, Pearson JP. Is gastric reflux a cause of otitis media with effusion in children? Laryngoscope. 2002;112:1930-4.

30. Karkos PD, Assimakopoulos D, Issing WJ. Pediatric middle ear infections and gastroesophageal reflux. Int J Pediatr Otorhinolaryngol. 2004;68:1489-92.

31. Sacher P, Stauffer UG. The Herbst triad: report of two cases. J Pediatr Surg. 1990;25:1238-9.

32. Calçado AC, Percope S, Gracia J, Junqueira JC. Herbst's triad: a rare clinical manifestation of gastroeosophageal reflux. In: Barry B, ed. In: II World Congress of Pediatric Gastroenterology, Nutrition and Hepathology. Paris: Lippincott Williams \& Wilkins; 2004. J Pediatr Gastroenterol Nutr. 2004:S421-2. 
33. Herbst J], Johnson DG, Oliveros MA. Gastroesophageal reflux with protein-losing enteropathy and finger clubbing. Am J Dis Child. 1976;130:1256-8.

34. Greenwald M, Couper R, Laxer R, Durie P, Silverman E. Gastroesophageal reflux and esophagitis-associated hypertrophic osteoarthropathy. J Pediatr Gastroenterol Nutr. $1996 ; 23: 178-81$.
Correspondence:

José Cesar da Fonseca Junqueira

Instituto de Puericultura e Pediatria Martagão Gesteira

Av. Brigadeiro Trompwiski, s/no

CEP 22260-090 - Rio de Janeiro, RJ - Brazil

Tel.: + 55 (21) 2590-4891

Fax: + 55 (21) 2590-4891

E-mail: cjunqueira@superig.com.br 